УДК $657.1+657.01$

\title{
С.А. Полухина
}

\section{НОВАЦИИ ЗАКОНОДАТЕЛЬСТВА В БУХГАЛТЕРСКОМ УЧЕТЕ ОСНОВНЫХ СРЕДСТВ}

Рассматриваются новации и изменения подходов к учету основных средств в соответствии с новыми федеральными стандартами бухгалтерского учета РФ (ФСБУ). Основные средства (ОС) представляют внеоборотный актив, заключающий материальную форму современных технологий и инноваций, используемых в производственном процессе и напрямую влияющий на себестоимость выпускаемой продукции. Адекватное отражение в финансовой отчетности основных средств представляется важным для целей пользователей. Нововведения законодательства содержатся в двух новых стандартах - ФСБУ 6/2020 «Основные средства» и ФСБУ 26/2020 «Капитальные вложения» и представляют актуальные шаги по гармонизации отечественного учета основных средств с международными стандартами финансовой отчетности (МСФО). В статье подробно проанализированы действующий ПБУ 6/01 «Учёт основных средств», нововведения законодательства и основные подходы МСФО в части учета и отражения в отчетности ОС. Изменения законодательства структурированы и проанализированы. Особый акцент сделан на элементах гармонизации учета и финансовой отчетности по определению лимита стоимости ОС, переоценки основных средств, порядку начисления амортизации основных средств. Основной вывод по результатам исследования позволяет утверждать, что финансовая отчетность, сформированная по новым правилам, будет значительно приближена к финансовым данным отчетности организации, представленной по МСФО.

Ключевые слова: бухгалтерский учет, федеральные стандарты бухгалтерского учета, международные стандарты бухгалтерского учета, основные средства, капитальные вложения, лимит стоимости, оценочные обязательства, первоначальная стоимость, переоценка, амортизация, обесценение.

DOI: $10.35634 / 2412-9593-2022-32-1-56-61$

\section{Введение}

Приоритетным направлением реформирования бухгалтерского учета в РФ является предоставление возможности хозяйствующим субъектам использовать право выбора современных способов и методов учета, в том числе признанных международной практикой.

В РФ с 1998 г. действует Программа реформирования бухгалтерского учета в соответствии с Международными стандартами финансовой отчетности. Первостепенные вопросы, реализуемые программой:

- формирование национальных стандартов учета и отчетности, обеспечивающих информацией пользователей, в первую очередь инвесторов;

- увязка реформы бухгалтерского учета в РФ с основными тенденциями гармонизации стандартов на международном уровне;

- оказание методической помощи организациям в понимании и внедрении реформированной модели бухгалтерского учета.

\section{Научная новизна}

В п. 1 ст. 21 Федерального закона № 402-Ф3 «О бухгалтерском учете» представлены стандарты четырех уровней (№ 402-Ф3) [1]:

1. Федеральные стандарты бухгалтерского учета.

2. Отраслевые стандарты, заключающие в себе особенности применения федеральных стандартов в отдельных видах экономической деятельности.

3. Рекомендации в области бухгалтерского учета.

4. Стандарты экономического субъекта.

При этом п. 4 ст. 20 № 402-Ф3 закрепляет «применения международных стандартов как основы разработки федеральных и отраслевых стандартов» [1].

В 2020 г. Минфин представил новые разработанные федеральные стандарты бухгалтерского учета, часть из которых касается гармонизации учета и отражения в отчетности основных средств. 
Следующие новые стандарты осуществили шаги по сближению с МСФО (IAS) 16 «Основные средства» и МСФО (IAS) 40 «Инвестиционная собственность» [2; 3]:

- ФСБУ 6/2020 «Основные средства»;

- ФСБУ 26/2020 «Капитальные вложения».

Новые ФСБУ 6/2020 и ФСБУ 26/2020 вступают в действие с 1 января 2022 г.

Сопоставим стандарты по учету основных средств в российской и международной практике в табл. 1.

Таблица 1

Стандарты по учету основных средств

\begin{tabular}{|c|c|}
\hline ФСБУ & МСФО \\
\hline ФСБУ 26/2020 «Капитальные вложения» & Сфера действия IAS 16 \\
\hline Главы в ФСБУ 6/2020 & IAS 40 «Инвестиционная недвижимость» \\
\hline ФСБУ 6/2020 «Основные средства» & IAS 16 «Основные средства» \\
\hline п. 38 ФСБУ 6/2020 ссылается на IAS 36 & IAS 36 «Обесценение активов» \\
\hline
\end{tabular}

\section{Цель исследования}

27 октября 2020 г. вступил в силу приказ Минфина № 204н от 17.09.2020 г., который утвердил ФСБУ 6/2020 «Основные средства» и ФСБУ 26/2020 «Капитальные вложения» (приказ № 204н) [5].

С 2021 г. вместо привычного ПБУ 6/01 «Основные средства» бухгалтеры могут применять новые стандарты [4].

Согласно ст.2 приказа № 204н, новые стандарты применяют, начиная с 01.01.2022 г. Досрочное применение с 01.01.2021 г. возможно после изменений в учетной политики.

С 01.01.2022 г. прекратят действовать ПБУ 6/01, а также приказ Минфина № 91н от 13.10.2003 г. «Об утверждении Методических указаний по бухгалтерскому учету основных средств» [6].

Практическая важность выявления основных изменений законодательства в бухгалтерском учете основных средств бесспорно представляется актуальной.

\section{Постановка задачи}

Гармонизация бухгалтерского учета основных средств требует проведения подробного сравнительного анализа ПБУ 6/01 «Основные средства», ФСБУ 6/2020 «Основные средства», ФСБУ 26/2020 «Капитальные вложения» и МСФО для целей практики бухгалтерского учета и аудита. Анализу подлежат элементы гармонизации подходов к учету основных средств, соответствия этих подходов МСФО.

\section{Методы}

Используя специальные методы, в том числе анализа и синтеза, индукции и дедукции, обобщения и сравнения, логического, сравнительного анализа, выявим изменения в учете основных средств, с которыми могут столкнуться бухгалтеры в 2021 г.

ФСБУ 6/2020 «Основные средства» и ФСБУ 26/2020 «Капитальные вложения» имеют ссылки к MCФО (IAS) 36 «Обесценение активов», МСФО (IFRS) 13 «Оценка справедливой стоимости», таким образом сближение международных и российских стандартов отчетности имеет место уже при логическом сравнении старых и новых отечественных стандартов.

Другим ключевым моментом ФСБУ является необходимость применения ретроспективно, то есть как если бы новые правила уже действовали с начала приобретения и использования конкретного актива. Это означает, что, к примеру, амортизацию, руководствуясь положениями ФСБУ 6/2020, необходимо определять по-новому. И балансовую стоимость основного средства на начало отчетного периода следует пересчитать. Соблюсти новые правила возможно единовременно, не делая пересчет за предыдущие годы.

Результаты анализа гармонизации учета основных средств представим в табл. 2. 
Таблица 2

Анализ результатов гармонизации учета основных средств по российским и международным стандартам

\begin{tabular}{|c|c|c|c|}
\hline $\begin{array}{l}\text { Элемент бухгалтер- } \\
\text { ского учета }\end{array}$ & ПБУ 6/01 & $\begin{array}{c}\text { ФСБУ 6/2020 } \\
\text { и ФСБУ } 26 / 2020\end{array}$ & $\begin{array}{l}\text { МСФО (IAS) } 16 \text { и } \\
\text { МСФО (IAS) } 40\end{array}$ \\
\hline \multicolumn{4}{|c|}{ Принятие ОС к учету } \\
\hline $\begin{array}{l}\text { Лимит стоимости } \\
\text { ОС }\end{array}$ & 40000 руб. & $\begin{array}{l}\text { Сумма, которая определена } \\
\text { с учётом информации, представ- } \\
\text { ляющей существенность }\end{array}$ & $\begin{array}{l}\text { Стоимость ОС } \\
\text { должна быть } \\
\text { надежно оценена }\end{array}$ \\
\hline «Малоценные» ОС & Запасы & Текущие расходы & Текущие расходы \\
\hline $\begin{array}{l}\text { Капитальные } \\
\text { вложения } \\
\text { в арендованные ОС }\end{array}$ & $\mathrm{OC}$ & Порядок учёта не установлен & $\begin{array}{l}\text { Увеличивают } \\
\text { стоимость } \\
\text { основного средства }\end{array}$ \\
\hline \multicolumn{4}{|c|}{ Определение первоначальной стоимости ОС } \\
\hline $\begin{array}{l}\text { Включение оценоч- } \\
\text { ного обязательства }\end{array}$ & Не учитывается & Предусмотрено & Предусмотрено \\
\hline $\begin{array}{l}\text { Порядок учета при } \\
\text { длительной отсроч- } \\
\text { ке (рассрочке) }\end{array}$ & $\begin{array}{l}\text { Номинальная сумма } \\
\text { обязательства }\end{array}$ & $\begin{array}{l}\text { Дисконтированная сумма обяза- } \\
\text { тельства, разница относится } \\
\text { на процентные расходы }\end{array}$ & $\begin{array}{l}\text { Дисконтированная } \\
\text { стоимость }\end{array}$ \\
\hline $\begin{array}{l}\text { Оценка при безвоз- } \\
\text { мездном получении }\end{array}$ & $\begin{array}{l}\text { Текущая рыночная } \\
\text { стоимость }\end{array}$ & Справедливая стоимость & $\begin{array}{l}\text { Справедливая } \\
\text { стоимость }\end{array}$ \\
\hline $\begin{array}{l}\text { Оценка при неде- } \\
\text { нежных расчетах }\end{array}$ & $\begin{array}{l}\text { Текущая рыночная } \\
\text { стоимость }\end{array}$ & Справедливая стоимость & $\begin{array}{l}\text { Справедливая } \\
\text { стоимость }\end{array}$ \\
\hline \multicolumn{4}{|c|}{ Переоценка ОС } \\
\hline $\begin{array}{l}\text { Переоцененная } \\
\text { стоимость }\end{array}$ & $\begin{array}{l}\text { Текущая } \\
\text { (восстановительная) } \\
\text { стоимость ОС }\end{array}$ & Справедливая стоимость & $\begin{array}{l}\text { Справедливая } \\
\text { стоимость }\end{array}$ \\
\hline $\begin{array}{l}\text { Периодичность } \\
\text { переоценки }\end{array}$ & $\begin{array}{l}\text { Регулярно, но не чаще } \\
\text { раза в год }\end{array}$ & Регулярно & Регулярно \\
\hline $\begin{array}{l}\text { Последовательность } \\
\text { переоценки }\end{array}$ & $\begin{array}{l}\text { Пересчёт } \\
\text { первоначальной } \\
\text { стоимости } \\
\text { и накопленной } \\
\text { амортизации }\end{array}$ & $\begin{array}{l}\text { Пересчёт первоначальной стои- } \\
\text { мости и накопленной амортиза- } \\
\text { ции (основной способ); } \\
\text { Первоначальная стоимость } \\
\text { уменьшается на накопленную } \\
\text { амортизацию и затем пересчиты- } \\
\text { вается до справедливой стоимо- } \\
\text { сти (допустимый способ) }\end{array}$ & Два подхода \\
\hline \multicolumn{4}{|c|}{ Доходные вложения в материальные ценности / инвестиционная недвижимость } \\
\hline $\begin{array}{l}\text { Выделение особой } \\
\text { группы ОС }\end{array}$ & $\begin{array}{l}\text { Предназначенные } \\
\text { для сдачи в аренду }\end{array}$ & Инвестиционная недвижимость & $\begin{array}{l}\text { Инвестиционная } \\
\text { недвижимость }\end{array}$ \\
\hline $\begin{array}{l}\text { Перевод ОС } \\
\text { из особой группы } \\
\text { в «основную» } \\
\text { и обратно }\end{array}$ & $\begin{array}{l}\text { Доходные вложения } \\
\text { в материальные ценно- } \\
\text { сти могут быть переве- } \\
\text { дены в ОС }\end{array}$ & Предусмотрен & Предусмотрен \\
\hline $\begin{array}{l}\text { Начисление } \\
\text { амортизации }\end{array}$ & В общем порядке & $\begin{array}{l}\text { По инвестиционной недвижимо- } \\
\text { сти, которая оценивается } \\
\text { по переоцененной стоимости, } \\
\text { амортизация не начисляется }\end{array}$ & $\begin{array}{l}\text { По справедливой } \\
\text { стоимости - аморти- } \\
\text { зация не учитывает- } \\
\text { ся, по первоначаль- } \\
\text { ной стоимости - } \\
\text { учитывается }\end{array}$ \\
\hline
\end{tabular}

Значительные изменения в учете и в отражении в отчетности произошли в отношении амортизации основных средств и капитальных вложений, результаты анализа изменений представлены в табл. 3. 
Таблица 3

Анализ учета амортизации основных средств по российским и международным стандартам

\begin{tabular}{|c|c|c|c|}
\hline $\begin{array}{c}\text { Элемент порядка } \\
\text { учета }\end{array}$ & ПБУ 6/01 & $\begin{array}{c}\text { ФСБУ 6/2020 и ФСБУ } \\
\text { 26/2020 }\end{array}$ & $\begin{array}{c}\text { МСФО (IAS) } 16 \text { и } \\
\text { МСФО (IAS) } 40\end{array}$ \\
\hline $\begin{array}{l}\text { Перепроверка } \\
\text { элементов } \\
\text { амортизации }\end{array}$ & $\begin{array}{l}\text { Происходит после модер- } \\
\text { низации (реконструкции } \\
\text { и т.п.). Остальные элемен- } \\
\text { ты не изменяются }\end{array}$ & $\begin{array}{l}\text { Срок полезного использо- } \\
\text { вания, ликвидационная } \\
\text { стоимость и способ начис- } \\
\text { ления амортизации прове- } \\
\text { ряются ежегодно }\end{array}$ & $\begin{array}{l}\text { Элементы амортизации } \\
\text { проверяются на наличие } \\
\text { признаков обесценения } \\
\text { ежегодно }\end{array}$ \\
\hline $\begin{array}{l}\text { Момент начала } \\
\text { и окончания } \\
\text { амортизации }\end{array}$ & $\begin{array}{l}\text { С } 1 \text { числа месяца следую- } \\
\text { щего за месяцем принятия } \\
\text { к учёту (выбытия) }\end{array}$ & $\begin{array}{lr}\text { С даты признания (выбы- } \\
\text { тия); или с } 1 \text { числа месяца, } \\
\text { следующего за месяцем } \\
\text { принятия к учету (выбытия) }\end{array}$ & $\begin{array}{l}\text { С момента готовности к } \\
\text { эксплуатации }\end{array}$ \\
\hline $\begin{array}{l}\text { Способы } \\
\text { начисления амор- } \\
\text { тизации }\end{array}$ & $\begin{array}{l}\text { Линейный; } \\
\text { уменьшаемого остатка; } \\
\text { по сумме чисел лет срока } \\
\text { полезного использования; } \\
\text { пропорционально объему } \\
\text { продукции (работ) }\end{array}$ & $\begin{array}{l}\text { Линейный; } \\
\text { уменьшаемого остатка; } \\
\text { пропорционально количе- } \\
\text { ству продукции }\end{array}$ & $\begin{array}{l}\text { Способ прямолинейного } \\
\text { списания; } \\
\text { способ списания про- } \\
\text { порционально объему } \\
\text { продукции; } \\
\text { способ уменьшаемого } \\
\text { остатка }\end{array}$ \\
\hline $\begin{array}{l}\text { База для } \\
\text { начисления } \\
\text { амортизации } \\
\end{array}$ & $\begin{array}{l}\text { Первоначальная (восстано- } \\
\text { вительная) стоимость }\end{array}$ & $\begin{array}{l}\text { Разница между первона- } \\
\text { чальной } \text { и ликвидационной } \\
\text { стоимостью }\end{array}$ & $\begin{array}{l}\text { Разница между первона- } \\
\text { чальной и ликвидацион- } \\
\text { ной стоимостью }\end{array}$ \\
\hline $\begin{array}{l}\text { Случаи } \\
\text { приостановления } \\
\text { начисления } \\
\text { амортизации } \\
\end{array}$ & $\begin{array}{l}\text { Консервация более } 3 \text { меся- } \\
\text { цев } \quad \text { или восстановление } \\
\text { более } 12 \text { месяцев }\end{array}$ & $\begin{array}{l}\text { Период времени, в котором } \\
\text { балансовая стоимость ОС } \\
\text { равна или меньше ликвида- } \\
\text { ционной }\end{array}$ & $\begin{array}{l}\text { Балансовая равна или } \\
\text { меньше ликвидационной }\end{array}$ \\
\hline
\end{tabular}

\section{Результаты}

Представленные новации законодательства в части учета основных средств указывают на значительное сближение российских подходов и МСФО. Из сравнительного анализа изменений законодательства можно определить основные тенденции нововведений.

Стоимость ОС не имеет больше законодательного лимита и организация вправе самостоятельно определять минимальное значение, при котором имущество признаётся основным средством, п. 4 ФСБУ 6/2020. В этой связи у хозяйствующих субъектов появилась реальная возможность нивелировать расхождения бухгалтерского и налогового учета, согласно которому к основным средствам не относятся объекты стоимостью до 100 тыс. рублей включительно.

Другая новация касается порядка учёта малоценных объектов основных средств: их стоимость должна относиться непосредственно на расходы. При этом с 2021 г. отнесение таких активов к запасам противоречит п. 3 ФСБУ 5/2019 «Запасы».

Организации могут выбирать группы основных средств, которые будут учитывать по переоценённой стоимости. Переоценка происходит по справедливой стоимости. Для каждой группы ОС предусмотрен один способ переоценки.

Если основные средства стали учитывать по переоценённой стоимости, то в будущих периодах переоценку необходимо проводить постоянно с целью соответствия справедливой стоимости. Для группы ОС компания устанавливает периодичность переоценки.

Критерий существенности для целей переоценки закрепляют в учётной политике.

Срок полезного использования, ликвидационную стоимость и способ начисления амортизации подвергают мониторингу в зависимости от изменений условий эксплуатации ОС. Выявленные изменения оценочных значений отражают перспективно.

$\mathrm{OC}$ некоммерческих организаций по новым правилам подлежат амортизации в общем порядке.

Амортизация начисляется с даты признания ОС или с месяца, следующего за месяцем признания, как установлено в учётной политике. Момент окончания начисления амортизации определяют аналогично. 
Временной период определения срока эксплуатации ОС позволяет начислять амортизацию линейным или способом уменьшаемого остатка.

Количество продукции (объёма работ в натуральном выражении), определяющие срок эксплуатации ОС, позволяют амортизировать пропорционально количеству продукции (объёму работ).

Способ устанавливают для каждой группы и он должен соответствовать поступлению будущих экономических выгод от использования ОС.

Правило соотнесения расходов на приобретение актива с доходами от его использования должно выполняться и учитываться при начислении амортизации.

В соответствии с ПБУ 6/01 проверка на обесценение была не предусмотрена. Новые ФСБУ 6/2020 и ФСБУ 26/2020 требуют проведения проверки на обесценение в соответствии с МСФО (IAS) 36 [7].

Вопрос наличия обесценения по основным средствам и капитальным вложениям возникает, когда присутствуют признаки обесценения. В стандарте они перечислены в п.12-14 и делятся на внешние и внутренние.

\section{Обсуждение}

Проведенное исследование позволяет сделать следующие выводы и выдвинуть ряд практических предложений. Актуальный учет и отражение в отчетности ОС с 2021 г. более достоверно представляет актив «основные средства в финансовой отчетности хозяйствующих субъектов». Новые стандарты позволяют гармонизировать национальные подходы к бухгалтерскому учету основных средств и сблизить общие правила учета и представления отчетности с международными стандартами финансовой отчетности.

Новые подходы к учету ОС представляются более гибкими для целей хозяйствующего субъекта, с другой стороны, наиболее достоверно демонстрируют характеристику актива основные средства для пользователей финансовой отчетности. Преимущества новых подходов к учету основных средств достигаются путем следующих базовых инструментов:

1) лимит стоимости актива определяется с позиций существенности и надежной оценки;

2) использование справедливой стоимости при признании актива;

3) использование дисконтированной стоимости в случае отсрочки при расчетах за актив;

4) учет влияния ликвидационной стоимости при определении амортизируемой стоимости;

5) переоценка актива;

6) регулярный пересмотр элементов амортизации;

7) регулярное тестирование актива на возможность приносить будующие экономические выгоды;

8) тестирование на обесценение.

Перед переходом к применению новых стандартов, таким образом, рекомендуется:

- провести полную и сплошную инвентаризацию основных средств и активов, потенциально способных получить статус основных средств;

- определить уровень существенности для целей определения лимита стоимости основных средств;

- зафиксировать в учетной политике организации приемлемые методы оценки и учета основных средств; баланс;

- определить ликвидационную стоимость основных средств, в текущий момент включенных в

- закрепить подходы к определению ликвидационной стоимости основных средств.

\section{Заключение}

С целью гармонизации учета и достоверного отражения в финансовой отчетности основных средств имеет смысл при применении ФСБУ 6/2020 «Основные средства» и ФСБУ 26/2020 «Капитальные вложения» закреплять вариативные правила, предусмотренные новым законодательством, в учетной политике хозяйствующих субъектов.

Система бухгалтерского учета организации, сформированная в соответствии с новыми нормами законодательства, вступающими в силу в 2021-2022 гг., ФСБУ 6/2020 «Основные средства» и ФСБУ 26/2020 «Капитальные вложения», позволит прозрачно, достоверно и полно представлять фи- 
нансовую информацию для целей пользователей отчетности. Финансовая отчетность, сформированная по новым правилам, будет значительно приближена к финансовым данным отчетности этой же организации, представленной по МСФО.

\section{СПИСОК ЛИТЕРАТУРЫ}

1. Федеральный закон от 06.12.2011 № 402-Ф3 «О бухгалтерском учете» // Собрание законодательства РФ. 12.12.2011. № 50. Ст. 7344.

2. МСФО (IAS) 16 «Основные средства». URL: http://www.consultant.ru/document/cons_doc_LAW_193590/.

3. МСФО (IAS) 40 «Инвестиционная недвижимость». URL: http://www.consultant.ru/document/ cons_doc_LAW_193538/.

4. Приказ Минфина России от 30.03.2001 № 26н «Об утверждении Положения по бухгалтерскому учету «Учет основных средств» ПБУ 6/01» (Зарегистрировано в Минюсте России 28.04.2001 № 2689). URL: http://www.consultant.ru/document/cons_doc_LAW_31472/71350ef35fca8434a702b24b27e57b60e1162f1e/.

5. Приказ Минфина России от 17.09.2020 № 204н «Об утверждении Федеральных стандартов бухгалтерского учета ФСБУ 6/2020 «Основные средства» и ФСБУ 26/2020 «Капитальные вложения» (Зарегистрировано в Минюсте России 15.10.2020 № 60399). URL: http://www.consultant.ru/document/cons_doc_LAW_365338/.

6. Приказ Минфина № 91н от 13.10.2003 «Об утверждении Методических указаний по бухгалтерскому учету основных средств». URL: http://www.consultant.ru/document/cons_doc_LAW_45140/.

7. МСФО (IAS) 36 «Обесценение активов». URL: http://www.consultant.ru/document/cons_doc_LAW_193674/.

Поступила в редакцию 09.12.2021

Полухина Софья Алексеевна, кандидат экономических наук,

доцент кафедры бухгалтерского учета и аудита

ФГБОУ ВО «Санкт-Петербургский государственный морской технический университет» (СПбГМТУ)

190121, Россия, г. Санкт-Петербург, ул. Лоцманская, 3

E-mail: sofia-05@list.ru

\section{S.A. Polukhina \\ NOVATIONS OF LEGISLATION IN ACCOUNTING FIXED ASSET}

DOI: $10.35634 / 2412-9593-2022-32-1-56-61$

Innovations and changes of approaches in accounting of fixed assets in accordance with the new Federal Account-ing Standards of the Russian Federation (FSB) are considered. Fixed assets (OS) represent a non-current assets including the material form of modern technologies and innovations used in the production process and directly affects the cost of manufactured products. Adequate reporting of fixed assets is important for users. The innovations of legislative are contained in two new standards - FSB 6/2020 «Fixed Assets» and FSB 26/2020 «Capital Investments», and represent current steps to harmonize the domestic accounting of fixed assets with international financial reporting standards (IFRS). The article analyzes in detail the current PBU 6/01 "Accounting of fixed assets", legislative innovations and the main approaches of IFRS in terms of accounting and reporting of fixed assets. Legislative changes are structured and analyzed. Special emphasis is placed on the elements of harmonization of accounting and financial reporting for determining the limit of the cost of fixed assets, revaluation of fixed assets, the procedure for calculating depreciation of fixed assets. The main conclusion based on the results of the study allows us to assert that the financial statements formed according to the new rules will be significantly closer to the financial data of the organization's financial statements presented under IFRS.

Keywords: accounting, federal accounting standards, international accounting standards, fixed assets, capital investments, value limit, estimated liabilities, initial cost, revaluation, depreciation, impairment.

Received 09.12.2021

Polukhina S.A., Candidate of Economics, Associate Professor at Department of Accounting and audit

State Marine Technical University of Saint-Petersburg (SMTU)

Lotsmanskaya st., 3, Saint Petersburg, Russia, 190121

E-mail: sofia-05@list.ru 